\title{
The effect of using micro teaching style supported by teaching techniques on some psychological skills and learning the long jump skill *Dr/ Sally Abdul- tawab Mahmoud Elbehwashy Summary :
}

The research has aimed at recognizing the effect of using the micro teaching style supported by teaching technology on Mental imagery and concentration, the level of technical performance of the long jump skill for the students of the first year at Faculty of Physical Education-University of Menofia. The researcher used the experimental approach on a sample contains (16) students from the first year at the Faculty of Physical Education -Menofia University, that has been divided into two groups, one experimental and the other is control contains, each is composed of ( 8) students. From the research tools :Wide standing broad jump, - run test for (30) meter From the beginning point, bending torso forward from standing Higher IQ Test -measuring the technical and digital performance for the long jump skill - a video device and its contents - a video camera - a display screen. From the statistical processors :SMA - Mediatorstandard deviation- medium- torsion modulus- Simple correlation coefficient $-\mathrm{T}$ test- improvement percentages. The research results have come up with: efficiency of micro teaching supported by teaching techniques in developing some psychological skill (mental imagery -consentration) In addition to learning and mastering the long jump skill.

\section{Introduction and research problem :}

The technical innovations

Despite what have been offered have acquired an increasing importance so as to increase by technology, from the datum of the educational process and upgrading it. technological educational medias that can serve the

* An Instructor in the department of field and track competitions faculty of physical education Menofiya University.

Assiut Journal For Sport Science Arts 
educational process, education in all different stages haven't gotten the benefit out of these medias, since their usage has still been limited. In addition, that requires from the teacher to know and understand scientific and technological changes and using the technological achievements and using them in the educational process.

Micro teaching is considered one of the modern teaching methods in which its usage appeared in the domain of methodology as an alternative to the traditional known methods where the technology of teaching is used in an obvious style in the micro teaching. Besides, the video device is also used as a feedback method to give better results.

It's worth mentioning that micro teaching has been linked with the presence of video that was first used to display models of teaching for under training teachers, then analyzing them, after that evaluate them Then, the unique feature of that device appeared where it was used to record training lessons then replaying them to provide feedback in order improve the teaching performance. Therefore, and from here we find that the usage of video in micro teaching style combines these two features, also displaying the example to the skill with its educational steps, Using video helps the teacher convey information for learners and frees him from the continuous work and decreases his effort which helps him to focus on the other educational tasks like guidance and analyzing the performance of the learners of the kinetics skills.

Mohamed Hassan Alawi (2002) (24) notes that success and failure of the athlete to show what is best in him of abilities and skills in sports competitions lies in the process of combining the kinetics and physical skills, also the psychological skills like the ability to relax focus and mental imagery, in addition to, the kinetic imagery is considered to be a brain skill 
where it recalls an action mentally, or a group of actions in the same sort and sequence of its actual performance .Lack of concentration is considered one of the problems in the athletic field because It leads to brain mistakes during a physical performance that's why focus training in attention concentration is one of the important psychological skills to achieve enjoyment . Besides, Excellence in performance will not occur unless the player is in the idealistic energy area, this is through controlling the attention on focus.

The multitude of field and track competitions requires from the teacher mastering the performance of different competitions that she teaches so that she can display it in a good way in front of the learners, and that might need displaying the skill that is required to learn in a slow way or in parts without ruining the skill so that the learner understands it better than describing the abstract skill or depending on the verbal description is not enough alone to teach the skill, also if the teacher can master the competition, it becomes hard to display it in a concentrated way and slow with commenting on the important parts of the skill that is needed to be learned.

In spite of the importance and simplicity of the long jump skill, the researcher from her work at teaching fields that field and track competitions for the students of the faculty of physical education El Menofia University noticed a failure in the level of technical and digital performance with the long jump skill for students of the first year, that seems clear from the exploratory conducted by the researcher on the students of the first year year 2011/2012 which showed 35 percent of the students have had a weak level of in that skill despite the effort made from the members of teaching. In addition, the researcher sees this in reference to the followed method of teaching (method of learning by order) which depends basically on the 
teacher in presenting the scientific material through the verbal explanation and the practical model for the long jump skill, that style doesn't give the learner a complete chance to compete and participate positively in the educational process, a matter that doesn't agree with the contemporary trends in the field of teaching methods to upyear the educational process as well as its output. Also, the lack of focus on the development of some psychological skills during the educational process, also the teacher is unable to follow up all the students to correct their mistakes during the lecture time and that doesn't give the students enough info related to the different sides of the skill and the theoretical knowledge related to the sides of different skill learning, under discussion, These reasons together have contributed in decreasing the level of the digital technical performance of the long jump skill, that are indicated in the results of the applied tests at the end of the study semester of the previous year in the Text material of field and track competitions.

The researcher points out that there is a possibility of benefiting from the means of techniques of teaching so as to upyear the technical and digital performance of the long jump skill which allows a success in the process of kinetic learning through building the kinetic virtualization of the performance for a learner. So, through the processes of displaying, the feedback has been used, and there has been a possibility to be affected positively in building and developing the kinetic learning for a learner. From here the importance of using the method of micro teaching supported by the techniques of teaching in keeping up with the development of educational strategies and upgrading them. So, through what has been mentioned, the current problem of research is represented in an attempt to recognize the effect of using the method of micro teaching that supported by the 
educational techniques as being considered as one of the modern teaching methods that improve the mental imagery and the concentration, in addition to the level of digital and technical performance for the skill of a long jump for student soft $h$ first year at the Faculty of Physical Education -University of Menofia .

Goals of Research

This research aims at recognizing the effect of using the method of micro supported by educational techniques on each of :

1- The mental imagery and concentration for students of first year at the Faculty of Physical Education -University of Menofia .

2- The level of technical and digital performance of the skill of long jump for students of first year at the Faculty of Physical Education -University of Menofia.

\section{The research hypotheses:}

1- There are significant differences between the two measurements pre and post for the experimental group in the mental imagery and concentration in favor of the post measurement, whereas there are not significant differences between the two measurements pre and post for control group in the mental imagery and concentration.

2- There are significant differences between the two post measurements for both groups, experimental and control in the in the mental imagery and concentration in favor of the experimental group.

3- There are significant differences between the two measurements pre and post for the two groups, experimental and control in level of digital technical performance in the skill of the long jump in favor of the post measurement.

4- There are significant differences between the two post measurements for the two groups, experimental and controlin level of digital technical performance in the skill of the long jump in favor of the experimental group .

Procedures of Research : Research method : 
The researcher used the experimental method for its suitability to the nature research, by using the experimental design which relies on the post pre measurement for two groups , one of them is experimental and the other is control .

Sample and population of research:

The sample of the research was selected in the purposive method from students of the first year at the Faculty of Physical Education Monfoia University, the first term( 2012/2013,) the total research population is (64) students and the researcher selected (16) students as a primary sample with a percentage of $25.00 \%$, they have been divided into two groups one is experimental and the other is control, each contains (8 )students and also (8) students as

a reconnaissance sample in order to rationing the tests, under discussion.

Moderation of distribution of the research sample individuals:

Homogeneity has been conducted between the research sample individuals that may have an effect on the experimental variable like growth rates (age-height weight-intelligence) and some physical variables (the muscle power legs, transitional speed, flexibility) in addition to some psychological skills (mental imagery and concentration) and the level of technical and digital performance of the of the long jump skill and these measures have been implemented (Homogeneity and parity) after conducting some scientific procedures for physical psychological high IQ tests , under discussion.

\section{Parity of both research groups:}

Parity between the two groups of research has been implemented (experimental control) in growing rates, physical and psychological changes in research and the level of the digital and technical performance for the long jump skill and that's to make sure that both groups are equivalent and that measure is considered the Pre measure for both the individuals of both groups of (experimental control) table 1. Clarifies this

Table (1) 
Significant differences between the control and experimental groups in growth rates and physical and psychological variables and the level of technical digital performance in the long jump.

\begin{tabular}{c|c|c|c|c|c|c}
\hline \hline Variables & $\begin{array}{c}\text { Measurement } \\
\text { unit }\end{array}$ & \multicolumn{2}{|c|}{ experimental group N=8 } & \multicolumn{2}{|c|}{ Control group N=8 } & Value \\
\hline \hline Age & One year & Mean & ST.DEVIATION & Mean & ST.DEVIATION & of T \\
\hline Length & Cm & 159,73 & 0,41 & 18,50 & 0,38 & 0.47 \\
\hline Weight & kG & 64,40 & 4,15 & 65,75 & 3,72 & 0,64 \\
\hline Intelligence & DEGREE & 33,50 & 3,98 & 32,50 & 4,11 & 0.46 \\
\hline $\begin{array}{c}\text { Muscle } \\
\text { capability for } \\
\text { legs }\end{array}$ & Meter & 1,40 & 0,10 & 1,35 & 0,15 & 0.71 \\
\hline $\begin{array}{c}\text { Transition } \\
\text { speed 30 meter } \\
\text { from start }\end{array}$ & Second & 4,66 & 0,51 & 4,79 & 0,66 & 0,41 \\
\hline $\begin{array}{c}\text { Flexibility of } \\
\text { Thigh and } \\
\text { torso }\end{array}$ & Cm & 8,25 & 2,83 & 7,85 & 2,91 & 0.26 \\
\hline Brain vision & Degree & 59,27 & 4,59 & 58,61 & 4,28 & 0.28 \\
\hline concentration & Number & 9,21 & 1,27 & 9,15 & 1,13 & 0.11 \\
\hline $\begin{array}{c}\text { Level of } \\
\text { artistic perf. In } \\
\text { the e long } \\
\text { jump }\end{array}$ & Degree & 0,83 & 0,55 & 0,77 & 0,50 & 0.21 \\
\hline $\begin{array}{c}\text { Level of } \\
\text { digital } \\
\text { performance in } \\
\text { the long jump }\end{array}$ & Meter & 2,19 & 0,24 & 2,10 & 0,22 & 0,73 \\
\hline \hline
\end{tabular}

Value of tabulated " $t$ " at level $0,05=2,145$

It is clear from table (10) that there is a lack of statistically significant differences at level 0.05 between the two groups, experimental and control in the rates of growing, and the psychological physical variables under discussion, also the technical digital performance of the long jump , that indicates a parity of the two groups in these variables

\section{Data collecting tools :}

First : physical tests :

1- $\quad$ Long jump broad jump test

2- $\quad$ Running test $30 \mathrm{~m}$, from start point . 
3- Torso bending forward test from standing still

Second: Mental and psychological tests under discussion:

\section{1- Mental} imagery

measurement: This measure was prepared by both Mohamed Elarabi Shamoon (1996) (21) under the subject of mental imagery in field of sports and it aims to recognize the degree of which the player can use senses during mental virtualization, it includes two sports situations :first : the individual practice. Second performance during competition and that's from the dimensions of the following mental imagery:

1- visual imagery

2- audio imagery ion

3- kinetic imagery

4- emotional imagery

5- inner imagery

6- declamatory imagery

2- Network concentration test:

Originally, this test was created by Dorthyharris (1987) to measure focus of attention, and its Arabic copy was created by Mohamed
Elarabi shamoon and Magda Ismail (1996) (21) ,it test includes a set of numbers from (0) to (99) inside squares, it is presented to the tested person for one minute and asked to follow the numbers in sequence, from the number selected for him, and that's by marking the square and the numbers he reached at the end of the minute with consideration that the number selected consists of two digits.

High Intelligence (IQ) test:

This test was created by Alsayd Mohamed khairi (1989) (6) and aims at measuring the mental power (Intelligence) and it works for both genders and all age stages specially the university stage.

Third: evaluation the performance of the long jump skill :

The researcher evaluated the performance of the long jump skill by having a trial contains (4) jurists, and a president (attachment 3) who have an experience in teaching in the field and track competitions for a period not less than (15) years and each one gives one score to a 
student and the president deletes the big and the small degree,then the score is calculated by using the average of both scores and it was evaluated out of $(10$, distributed as follows (2) degrees for the approach run up stage, (3) for the take off stage, (3) for the flight through the air stage (2) for the landing stage).

Fourth: measurement of the digital performance for the long jump skill:

The measurement of the digital performance for the long jump skill was measured with special rules and conditions that have been determined by the law of the International of Athletics Federation for Amateurs where it was measured from the nearest trace the student leaves inside the jump hole till the take-off board.

Pre measurements:
Before doing the pre measurements, the researcher taught two educational units of for the members of the basic research sample, so that all members of sample could reach a specific level where the researcher could implement pre measurements, $11 / 10 / 2012$ to $15 / 10 / 2012$. The researcher has implemented the Pre measurements of the psychological variables and the technical and digital performance of the long jump skill for both the members of both groups the experimental and the control from $17 / 10 / 2012$ to $21 / 10 / 2012$.

\section{The main experiment:}

The researcher used the standard font of the micro teaching which has been indicated by George Brown (2005)(12), it consists of 3 important stages clarified by the following table:

Table (2)

\section{the standard font of the micro teaching :}

\begin{tabular}{l|l|l}
\hline Re teaching & Watching and criticism & Reeducation \\
\hline
\end{tabular}

First: Learning by micro teaching by using the visual recorder for the experimental group:

A learner watches the explanations of educational photographed model of the skill of the long jump for (7) minutes accompanied with steps and the technical performance, which is recorded Acoustically and visually then 
the learner starts general warm up for(10) minutes, Then training on skill performance for (10) minutes, followed by watching and criticizing session for (15) minutes so as to correct learners mistakes, in addition to some notes concerning the method of performance, after this teaching is repeated for another time with the correction of technical mistakes for (15) minutes, in addition to(3) minutes for conclusion.

Second: the control group (learning about it) style:

the educated public and private warm-up in 15 minutes, then the parameter performance of a practical model for the skill of the long jump with providing explanation verbal appropriate in a period of 7 minutes, and then training on educational steps in for (35) minutes, including the main part, and in this part of the teacher to provide feedback on the performance of the educated to be able to fix technical mistakes, and a period of (3) minutes of the final part.

The main research experiment was conducted in the period of $23 / 10 / 2012$ to $03 / 12 / 2012$ and that's 6 consecutive weeks noting that the period for the Practical lesson (90) minutes (2) sessions a week, and the duration of every single lesson (60) minutes, (12) educational lessons are taught during this period, the rest (30) minutes for the practical lesson for the lessons of the track and field for the first year students in the faculty

\section{Dimensional measures:}

The dimensional measurements were conducted to both members of the groups : experimental and controlling from $4 / 12 / 2012$ to $6 / 12 / 2012$ in the psychological variables, and the level of digital technical performance for the long jump skill with the same conditions and order of pre measurements

Table (3) 
Significant differences between the two measurements pre and post for the experimental group in the psychological variables, subject of research. $(\mathrm{N}=8)$

\begin{tabular}{c|c|c|c|c|c|c|c|c}
\hline \hline Variables & $\begin{array}{c}\text { Measurement } \\
\text { unit }\end{array}$ & \multicolumn{2}{|c|}{ Pre measurement } & \multicolumn{2}{c|}{ Post measurement } & $\begin{array}{c}\text { Difference } \\
\text { between } \\
\text { the two } \\
\text { SMA }\end{array}$ & $\begin{array}{c}\text { VALUE } \\
\text { OF T }\end{array}$ \\
\hline \hline $\begin{array}{c}\text { mental } \\
\text { imagery }\end{array}$ & degree & $\mathbf{5 9 , 2 7}$ & $\mathbf{4 , 5 9}$ & $\mathbf{6 7 , 0 0}$ & $\mathbf{4 , 1 6}$ & 7,73 & $* 4,49$ \\
\hline \begin{tabular}{c} 
concentration \\
\hline \hline
\end{tabular} & Number & $\mathbf{9 , 2 1}$ & $\mathbf{1 , 2 7}$ & $\mathbf{1 1 , 5 0}$ & $\mathbf{1 , 1 1}$ & 2,29 & $* 3,21$ \\
\hline
\end{tabular}

\section{Value of Tabulated " $T$ " at the level of $0,05=2,365$ *significance} at level 0,05

Seen from the table (3) There are significant differences at the 0.05 level between the measurement pre and post experimental group in

\section{Table (4)}

Significant differences between the two measurements pre and post for the control group in the psychological variables, subject of research

\begin{tabular}{|c|c|c|c|c|c|c|c|}
\hline \multirow{2}{*}{ Variables } & \multirow{2}{*}{$\begin{array}{c}\text { Measurement } \\
\text { unit }\end{array}$} & \multicolumn{2}{|c|}{ Pre measurement } & \multicolumn{2}{|c|}{ Post measurement } & \multirow{2}{*}{$\begin{array}{c}\text { Difference } \\
\text { between } \\
\text { the two } \\
\text { SMA } \\
\end{array}$} & \multirow{2}{*}{$\begin{array}{c}\text { VALUE } \\
\text { OF T }\end{array}$} \\
\hline & & Mean & ST.DEVIATION & Mean & ST.DEVIATION & & \\
\hline $\begin{array}{c}\text { mental } \\
\text { imagery }\end{array}$ & degree & 58,61 & 4,28 & 60,23 & 4,31 & 1,62 & $\mathbf{0 , 8 1}$ \\
\hline concentration & Number & 9,15 & 1,13 & 9,91 & 1,22 & $\mathbf{0 , 7 6}$ & $\mathbf{0 , 4 5}$ \\
\hline
\end{tabular}

Value of Tabulated " $T$ " at level $0,05=2,365$

It is seen from the table

(4) lack of statistically significant differences at the 0.05 level between pre and post measurement of the control group on psychological variables (mental imagery concentration).

The researcher refers to the improvement in the mental 
imagery and focus in the experimental group of the to the positive effect of the micro teaching style supported with teaching techniques which is concludes the video and the script which got the students to focus and mental virtualization, while the controlling group just displayed the practical example and the verbal explanation that doesn't give the student a chance to mental virtualization and recalling the steps of performing the skill, this result is the same as what Monzer Kamal (1999)(32) said that using the styles of technological education leads to engaging all the senses of the student in the educational process which improves the mental processes.

by this the first hypothesis of research is achieved.

Table (5)

Significant differences between the two Pre measurements for the two groups- experimental and the control in the psychological variables, subject of research

\begin{tabular}{l|c|c|c|c|c|c}
\hline \hline Variables & $\begin{array}{c}\text { Measurement } \\
\text { unit }\end{array}$ & \multicolumn{2}{|c|}{ Pre measurement } & \multicolumn{2}{c|}{ Post measurement } & $\begin{array}{c}\text { VALUE } \\
\text { OF T }\end{array}$ \\
\hline & & Mean & ST.DEVIATION & Mean & ST.DEVIATION & \\
\hline $\begin{array}{l}\text { mental } \\
\text { imagery }\end{array}$ & degree & 67,00 & 4,16 & 60,23 & 4,31 & $2,99^{*}$ \\
\hline concentration & Number & 11,50 & 1,11 & 9,91 & 1,22 & $2,56^{*}$ \\
\hline \hline
\end{tabular}

Value of $T$ at level $0,05=2,145$ significance at level $0,05 *$

Seen from the table (5) there are significant differences at the 0.05 level between the two measurements Badaan the experimental and control groups in the psychological variables (mental imagery concentration) for the experimental group.
The researcher attributes the superiority of the experimental group on the controlling group in the psychological skills in the research to the effectiveness of the micro teaching style that helped to sort the educational process in a correct way, in the memory also helped the 
student focus on mental tasks and how fast the skill can be obtained, in addition to focusing on each part of the skill which leads to the improvement of the psychological skills of students.

The researcher attributes nonexistence of any improvements for the members of the controlling group in the psychological skills in the

\section{Table (6)}

Significant differences between the two measurements pre and post for the experimental group in the level of the digital technical performance of the skill of the long jump. $N=8$

\begin{tabular}{|c|c|c|c|c|c|c|c|}
\hline \multirow[t]{2}{*}{ Variables } & \multirow[t]{2}{*}{$\begin{array}{c}\text { Measurement } \\
\text { unit }\end{array}$} & \multicolumn{2}{|c|}{ Pre measurement } & \multicolumn{2}{|c|}{ Post measurement } & \multirow{2}{*}{$\begin{array}{c}\text { Difference } \\
\text { between } \\
\text { the two } \\
\text { SMA }\end{array}$} & \multirow[t]{2}{*}{$\begin{array}{l}\text { VALUE } \\
\text { OF T }\end{array}$} \\
\hline & & Mean & ST.DEVIATION & Mean & ST.DEVIATION & & \\
\hline $\begin{array}{l}\text { The level of } \\
\text { technical } \\
\text { performance } \\
\text { in the long } \\
\text { jump }\end{array}$ & Degree & 0.83 & 0.55 & 8.81 & 0.93 & 7.98 & $18.93 *$ \\
\hline $\begin{array}{ll}\text { Digital level } \\
\text { performance } \\
\text { in long } \\
\text { jump }\end{array}$ & Meter & 2.19 & 0.24 & 3.55 & 0.28 & 1.36 & $10.19 *$ \\
\hline
\end{tabular}

Value of tabulated" T" at level 0,05 =2,365 *significance at level 0,05 Seen from the table (6) there are significant differences at the 0.05 level between the measurement pre and post experimental group in the level of technical performance and digital skill long jump for the 
benefit of the dimensional measurement.

The researcher attributes the improvement of the performance of the digital and technical performance of the skill of long jump in the members of the experimental group to the usage of the micro teaching style supported with teaching techniques that gives the total chance to the students to know their technical abilities from the sides of strength and weakness in the performance of the skill in the research and benefiting from the feedback of the teacher and the students in criticizing the students and that's what the following agreed with what said by AbdEILatif ben Hamad and Mohdi Salem (2004) (3) and EmamMokhtar and others (2006) (11) that the educational means intrigues the student and increases his experience and makes him more ready to learn and if it was used correctly then the students hurry to learn and improve their learning results .

\section{Table (7)}

\section{Significant differences between the two measurements pre and} post for the control group in the level of the digital technical performance of the skill of the long jump. $N=8$

\begin{tabular}{l|c|c|c|c|c|c|c}
\hline \hline Variables & $\begin{array}{c}\text { Measurement } \\
\text { unit }\end{array}$ & \multicolumn{2}{|c|}{ Pre measurement } & \multicolumn{2}{|c|}{ Post measurement } & $\begin{array}{c}\text { Difference } \\
\text { between } \\
\text { the two } \\
\text { SMA }\end{array}$ & $\begin{array}{c}\text { VALUE } \\
\text { OF T }\end{array}$ \\
\hline \hline $\begin{array}{l}\text { mental } \\
\text { imagery }\end{array}$ & degree & 0,77 & 0,50 & 7,35 & 0,69 & 6,58 & $15,17 *$ \\
\hline $\begin{array}{l}\text { Attention } \\
\text { focus }\end{array}$ & meter & 2,10 & 0,22 & 3,17 & 0,26 & 1,07 & $8,31 *$ \\
\hline \hline
\end{tabular}

Value of Tabulated "T" at level 0,05 =2,365 *significance at level 0,05

Seen from the table (7) there are significant differences at the 0.05 level between pre and post measurement of the control group in the level of technical performance and digital skill long jump for the 
benefit of the dimensional measurement.

The researcher attributes the improvement of the digital and technical performance of the long jump skill at the members of the controlling group to the presence of the teacher during the lesson and her ability to perform the practical example and the verbal explanation to the skill plus correcting the technical errors once appeared which led to learning the long jump skill.
And this result agrees with what Mofti Ibrahim (2002) (19) said that the level of performance of the players depends on the ability of the coach to explain the kinetic skill from the right position of the body and the repetition of the performance, also modifying it leads to improving the performance of the skill .

And by this the third hypothesis of the research is achieved.

Table (8)

Significant differences between the two Pre measurements for the two groups , control and experimental in the level of the digital technical performance of the skill of the long jump.

\begin{tabular}{l|c|c|c|c|c|c}
\hline \hline Variables & $\begin{array}{c}\text { Measurement } \\
\text { unit }\end{array}$ & \multicolumn{2}{|c|}{ Pre measurement } & \multicolumn{2}{c|}{ Post measurement } & $\begin{array}{c}\text { VALUE } \\
\text { OF T }\end{array}$ \\
\hline \hline & & Mean & ST.DEVIATION & Mean & ST.DEVIATION & \\
\hline $\begin{array}{l}\text { mental } \\
\text { imagery }\end{array}$ & degree & $\mathbf{8 , 8 1}$ & $\mathbf{0 , 9 3}$ & $\mathbf{7 , 3 5}$ & $\mathbf{0 , 6 9}$ & $\mathbf{3 , 3 2 *}$ \\
\hline \begin{tabular}{l} 
concentration \\
\hline \hline
\end{tabular} & meter & $\mathbf{3 , 5 5}$ & $\mathbf{0 , 2 8}$ & $\mathbf{0 , 2 8}$ & $\mathbf{3 , 1 7}$ & $\mathbf{2 , 7 1 *}$ \\
\hline
\end{tabular}

Value of "T" at the level of $0,05=2,145$ significance at a level of $0,05^{*}$

The researcher attributes the improvement in the digital and technical performance of the long jump skill at the members of the experimental group compared to the controlling group to the effect of using the micro teaching style supported with teaching techniques that deals with a small amount of students which allows them to gain much more from the lesson. Besides, that style depends on 
teaching, feedback, re teaching a and fixing the technical errors which had a big effect on the supremacy of the experimental group .

This result agrees with what Mohsen

Homos (1997)(29)said that the micro teaching depends on displaying examples and pictures of the skill to the students and analyzing it to provide feedback to the students then practicing on the kinetic performance and fixing what occurred of technical errors and that's how it helps develop the technical performance more than other educational methods .

And by this the fourth hypothesis of the research is achieved.

\section{Conclusions:}

1- The effectiveness of the micro teaching style supported with teaching techniques in developing some psychological skills
(Mental

imageryconcentration) mastering and learning the long jump skill.

2- Teaching by order style doesn't have any effectiveness in developing some psychological skills (mental imagery -concentration) .

3- Teaching by order is effective in learning the long jump skill.

4- Micro teaching style is more effective than teaching by order in developing the psychological skills (mental imagery -concentration) and learning the long jump skill.

5- The supremacy of the micro teaching style supported with teaching techniques on the teaching by order in the dimensional measure on the tribal measure in some psychological skills (mental imagery -concentration) and learning the long jump skill.

\section{Recommendations:}

1- The necessity of using the micro teaching style supported with teaching techniques in some 
psychological skills (mental imagery -concentration) mastering and learning the long jump skill.

2- Provide requirements of the micro teaching style (computer - video camera video - display) in the departments of field and track competitions for students in the faculties of physical education. 3- Encouraging the members of the educational department on using the nontypical methods in teaching the track and field competitions.

4- The importance of teaching methods that gives an effective role to the teaching technology which agrees with the upgrading and development of the educational process.

5- Doing more scientific studies to know more about the effect of using the micro teaching style supported with teaching techniques in developing the other psychological skills in the track and field competitions.

References :
1- $\quad$ Abd el magidnashwaty (2006): Educational Psychology, Alforkan house for publishing and distribution, Oman,Jordan.

\section{2- Abd Elhameed Sharaf} (2000): Education technology in physical education, Alketab publishing house Cairo.

3- AbdEllatif Ben Hamad ,Mohdi Salem (2004): field education and education skills, Alobikan library,Al Ryiad City,Saudi Arabia.

4- Adnan Darwish, AmeenAlkholi, Mahmoud Annan (1994): Physical Education School- class teacher guide and student practical education, 3th edition, Al fekrelarabi Publishing house, Cairo.

5- Ahmed AmeenFawzi (2003): Principles of athletic psychology,concepts, applications, Al fekrelarabi Publishing house, Cairo .

6- Alsayed Mohamed Khairi (1989): Higher IQ Test (instructions and applications), 
Publishing

house

Elnahdaelarabia, Cairo.

7- Alumsdaine

(2002)

:Unescoeducational

Media

Conference Recomunetions in

A .v c Communication

Review, vol .2.

8- Atef El Sayed (2002):

Education technology and information using computer and videoIn teaching and learning,Printing house Ramadan\& Sons, Cairo.

9- Bastawesy

Ahmed

Bastawesy (1997): Track and field competitions, Publishing house of Al fekrelarabi, Cairo .

10- Davis,R.,(1999) ： The Effectiveness of Micro Teaching and video tapes in tramingprospctive elementary teachers in spifcteachical, oniouniverity.

11- EmamMokhtar,

Ahmed Alnagdi, Salah Arafa, Ali Rashed ,HasanAlkersh(2006): teaching skills, Zahra El shrouq library, Cairo .

12- George brown (2007) micro teaching translated by
Mohamed Reda Elbaghdadi and Hayam Mohamed Reda, Publishing house of $\mathrm{Al}$ fekrelarabi, Cairo.

\section{3- Hamed Mohamed}

Elkomi (2008): The effect of multimedia on developing the mental imagery and consentrationin some defensive skills in hand ball, Journal of Sports Science and Arts, Vol 31,first issue, Faculty of physical education females, Helwan University

14- Hesham Mohamed Anwar Abdul Hamid (2007): "the use of mini-teaching on the performance of some of the basic skills level in handball with the students the second cycle of basic education effect", Journal of Science and Arts Sports, Vol. (26), Faculty of Physical Education Girls, HelwanUniversity.Abd el magidnashwaty 2006 psychology Alforkan house for publishing and distribution Oman

15- Hossam Eldeen Nabih Abdu Fatah (2002): The effect 
of using some education technology in learning some skills in hand ball,Ph.D, Faculty of physical education, Al-Azhar University house, Cairo.

16- Kasem Hassan Hossien (2010): Encyclopedia of track and field, al fekr publishing house, Oman ,Jordan 17- Margritis ,A., (2004) : Micro Teaching asa ComponentinTroiving Program of Prospective Teachers، Dissertation Abstracts International, Vol., 55, No., 3 . 18- Medhat Unisabd El Raziq (2004): the Effectiveness of the micro teaching method using visual devices in learning some attack skills at basketball, Magazine theories and applications, $50^{\text {th }}$ vol, faculty of physical education males, Alexandria University.

19- Mofty

Hamad (2002): Athletic training educational, Almokhtar Publishing house, Cairo.
20- Mohamed el sayed Ali (2002): Education technology and multimedia, Al fekrelarabi Publishing house, Cairo.

21- Mohamed

Elarabi

Shamoon (1999): Ethletic psychology and psychology measures, MarkazElketab Publishing house, Cairo.

22- Mohamed Elarabi Shamoon (2001): Mental training in the sports, $2^{\text {nd }}$ Edition,Alfekrelarabi

Publishing house, Cairo.

23- Mohamed Hassan Alwai (1998): Sports Psychology, $5^{\text {th }}$ Edition, Al fekrelarabi Publishing house, Cairo.

24- Mohamed Hassan

Alwai (2002): Psychology of training and competition, $\mathrm{Al}$ fekrelarabi Publishing house, Cairo.

25- Mohamed Mohamed Abd Allah (2001): Comparison between some teaching methods on important skills for the games,Master Thesis, faculty of physical 
education males,Helwan University.

26- Mohamed

Saad

Zaghlol, Makarem Abo Harga, Hani Said (2001): Education technology and methods in physical education,Alketab Publishing house, Cairo.

27- Mohamed Saad Zaghlol, Mostafa El Sayeh (2004): Technology for Preparation and qualification for teachers of Physical Education, Alwafaa Publishing house, Alexandria.

28- Mohamed

Sobhi

Hasaneen (2001): Calibration and measure in physical education, part $1,4^{\mathrm{TH}}$ Edition, Al fekrelarabi Publishing 29- Mohsen Hommos (1997): Leader in the teaching of Physical Education ,almaraef , Alexandria.

30- Mostafa

badran, Ebrahim Metawea, Mohamed Atia (2002): Educational ways, $2^{\mathrm{ND}}$ Edition, Anglo Egyptian library, Cairo.

\section{1- Mostafa Elsaieh, Salah} Anas (2000): Evaluate the use of educational technology in the teaching of the Faculty of Physical Education, the Arab Republic of Egypt "curricula, quality education strategy first scientific conference in Egypt, Faculty of Specific Education Damietta, Mansoura University.

32- Munzer Mohamed Kamal (1999): "The effect of using the entrance in the teaching of mathematics using the computer to collect firstyear middle school students and maintain the impact of their learning and their attitudes towards it," $\mathrm{PhD}$ thesis, Institute of Educational Studies and Research, Cairo University.

\section{3- Nashwa Mahmoud} Nafi '(2005): "The effectiveness of using hyper media on the development of perception and mental Imagery and consentrationand their relationship improves performance motor creative in the exercise rhythmic for the 
students of the Faculty of Physical Education," Journal of theories and applications, Vol (56), Faculty of Physical Education for male, Alexandria University.

34- Nielson,K.,(2004): The Eeffects of Video - Cueing Selected Teaching Behavior in Physical Education Classes, Journal of Teaching inPhysical Education ,Vol.,61.

\section{5- Osama Kamel Rateb} (2004): Training the psychological skills . application in sports,2 Edition, Publishing house of $\mathrm{Al}$ fekrelarabi, Cairo.

36- Pelberg ,N., (1996): Comceptual and Theoretical Bases For Micro Teaching, The International Encgclopedia of Education Technology.

\section{7- Rushall, B.,(1998):}

Imagery Training in Sports. Web site: http://www. rohan.sdsu.edu/dept/coachsci/vo 1 26/rushall 3.htm.

\section{8- Taghreed Mohamed}

Aleraqi(2006): The effect of using micro teaching style on learning some offensive skills in field hokey, ,Journal of Sports Science and Arts, Vol (25), Faculty of physical education females, Helwan University .

\section{9- Wael Jalal Assiouti} (2007): "Teaching the impact of micro-registered using the Visible on the performance of some of the skills level of the compound attack in epee", the scientific journal of Physical Education and Sports, No. (47), Benin Faculty of Physical Education, Helwan University. 40- Zinab

Helmy Elsherbiny (1988): Micro teaching using video to train on performance in teaching, Education Technology Magazine, Kuwait. 